\title{
Digitoxin and its synthetic analog MonoD have potent antiproliferative effects on lung cancer cells and potentiate the effects of hydroxyurea and paclitaxel
}

\author{
JUAN SEBASTIAN YAKISICH ${ }^{1}$, NEELAM AZAD $^{1}$, RAJKUMAR VENKATADRI $^{1}$, YOGESH KULKARNI ${ }^{1}$, \\ CLAYTON WRIGHT $^{1}$, VIVEK KAUSHIK ${ }^{1}$, GEORGE A. O'DOHERTY ${ }^{2}$ and ANAND KRISHNAN V. IYER ${ }^{1}$ \\ ${ }^{1}$ Department of Pharmaceutical Sciences, School of Pharmacy, Hampton University, Hampton, VA 23668; \\ ${ }^{2}$ Department of Chemistry, Northeastern University, Boston, MA 02115, USA
}

Received July 10, 2015; Accepted July 27, 2015

DOI: $10.3892 / o r .2015 .4416$

\begin{abstract}
Despite significant advances in the understanding of lung cancer biology, the prognosis of cancer patients remains poor. Part of the failure of anticancer therapy is due to intratumoral heterogeneity in these patients that limits the efficacy of single agents. Therefore, there is an urgent need for new anticancer drugs or drug combination regimens that possess increased activity against all cellular subtypes found within the tumor. In this study, we evaluated the in vitro antiproliferative activity of the cardiac glycosides (CGs) digitoxin and its synthetic analog MonoD on H460 lung cancer cells grown under different culture conditions. The CGs were tested alone in $\mathrm{H} 460$ cells under routine culture as well as in cells growing under short (24-72 h) and prolonged serum starvation (7 days) in order to evaluate the activity of drugs on cancer cells under varied degrees of proliferation. Our results showed that both CGs, and MonoD in particular, have potent antiproliferative activity at clinically relevant concentrations against cells in all the tested culture conditions. In contrast, paclitaxel, hydroxyurea and colchicine were only active in cells growing in routine culture conditions, and relatively inactive in serum-starved conditions. Importantly, both CGs were able to potentiate the effect of clinically relevant concentrations of hydroxyurea or paclitaxel in serum-starved conditions. When paclitaxel was used in combination with CGs, the highest antiproliferative effect was obtained when paclitaxel was administered first, followed by either digitoxin or MonoD. Our results indicate that CGs have potential clinical applications in translational oncology especially in combination with other drugs, and
\end{abstract}

Correspondence to: Dr Anand Krishnan V. Iyer, Department of Pharmaceutical Sciences, School of Pharmacy, Hampton University, Hampton, VA 23668, USA

E-mail: anand.iyer@hamptonu.edu

Abbreviations: PX, paclitaxel; Dig, digitoxin; HU, hydroxyurea

Key words: lung cancer, cardiac glycosides, digitoxin, MonoD, combination therapy, paclitaxel, hydroxyurea warrants further investigation of CGs in more advanced preclinical models of lung cancer.

\section{Introduction}

Lung cancer is the leading cause of cancer-related deaths among both men and women, with an estimated 228,190 cases of lung cancer in the United States and 159,480 deaths from the disease in 2013 (1). The majority of patients are diagnosed at an advanced stage when curative treatment options are limited (2). The overall five-year survival rate is only $16 \%$ (3), and the prognosis has remained unchanged for the last three decades.

Digitoxin (Dig) is an FDA approved drug for the treatment of cardiac disease. The therapeutic plasma levels of digitoxin is considered to be in the ranges of $13-33 \mathrm{nM}(4,5)$ and up to $46 \mathrm{nM}$ (6). Dig at micromolar concentrations inhibits the $\mathrm{Na} / \mathrm{K}-\mathrm{ATPase}$, but it is believed that at nanomolar concentrations, it activates the $\mathrm{Na}^{+} / \mathrm{K}^{+}$-ATPase signalosome to transmit intracellular signals, leading to anticancer effects (7). Paclitaxel (PX) remains a first-line treatment for advanced NSCLC in the United States (8). PX at therapeutic concentrations acts as a microtubule stabilizer, inducing cell cycle arrest in the $\mathrm{G}_{2} / \mathrm{M}$ phase; its dose-limiting toxicities are neutropenia and peripheral neuropathy (9). Resistance to PX is associated with expression of multidrug resistance efflux pumps and tumor hypoxia (10). In patients, relevant plasma concentrations of PX are between 80-280 $\mathrm{nM}$ (11), but peak concentration after intravenous infusion can reach $10 \mu \mathrm{M}$ (12). In the case of hydroxyurea (HU), plasma levels of $1 \mathrm{mM}$ can be achieved and maintained in patients (13). These concentrations are high enough to inhibit in vitro the proliferation of lung cancer cells, but as single drugs neither PX nor HU have been successful.

Lung cancers display intratumoral heterogeneity $(14,15)$. It is known that complex crosstalk exists between cancer cells and the stromal microenvironment via the secretion of a variety of growth factors (3). Other environmental factors such as hypoxia, blood flow, $\mathrm{pH}$ have profound effects on this interaction and contribute to the intratumoral heterogeneity of lung cancer. Different tumor microenvironments are characterized by different cell populations with varying rates of 
proliferation and varying degrees of selective pressures such as oxygen, acidity, and tumor growth factors (16). Therefore, in addition to testing anticancer drugs growing under routine culture conditions [media supplemented with fetal bovine serum (FBS)] studying the effect of these compounds in serum starved cells that in part mimic the behaviour of low proliferating cells, such as cancer stem-like cells, may offer additional information on the chemosensitivity of cancers in general. In this study we characterized the anticancer activity of clinically relevant concentrations of Dig and its synthetic analog MonoD on H460 lung cancer cells growing under different culture conditions. We also evaluated the effect of these cardiac glycosides (CGs) in combination with clinically relevant concentrations of paclitaxel and hydroxyurea.

\section{Materials and methods}

Drugs. Dig and MonoD ( $\beta$-D-digitoxose) were stored as stock solution $(10 \mathrm{mM})$ in DMSO in glass containers. Dig was obtained from Sigma-Aldrich (St. Louis, MO, USA). MonoD was synthesized using a methodology previously described (17). Final dilutions were freshly prepared in culture media before use. All control treatments were supplemented with the highest concentration $(\sim 0.001 \%)$ of DMSO used in drug treatment. HU, PX and colchicine were purchased from Sigma-Aldrich. HU and colchicine were prepared as stock solution (500 and $10 \mathrm{mM}$, respectively) in distilled sterile water and stored in aliquots at $-20^{\circ} \mathrm{C}$. PX was prepared as stock solution of $1 \mathrm{mM}$ in DMSO and stored in aliquots at $-20^{\circ} \mathrm{C}$.

Cell culture. The human lung epithelial cancer cell line NCI-H460 was obtained from American Type Culture Collection (Manassas, VA, USA). This cell line is considered highly resistant to chemotherapy (1). NCI-H460 cells were cultured in complete media (CM, RPMI-1640 supplemented with 5\% FBS, 2 mM L-glutamine, $100 \mathrm{U} / \mathrm{ml}$ penicillin, and $100 \mathrm{mg} / \mathrm{ml}$ streptomycin) (18). All cells were cultured in a $5 \% \mathrm{CO}_{2}$ environment at $37^{\circ} \mathrm{C}$.

Short-term antiproliferative effect of Dig and MonoD (MTT assay). Cells $(\sim 2,000$ cells/well $)$ were plated in 96-well cellculture microplates (Costar, USA) and incubated overnight in cell culture medium to allow them to adhere. Cells were then exposed to the appropriate concentration of drug or vehicle for 24-72 h. Depending on the culture conditions, drugs were added in either CM or serum-free media (SFM, same as CM but without FBS). Cell viability was evaluated by the MTT (Sigma-Aldrich) assay. The absorbance of solubilized formazan was read at $570 \mathrm{~nm}$ using Gen 52.0 All-In-One microplate reader (Bio-Tek Instruments Inc.). In all cases, the highest concentration of DMSO was used in the control and this concentration was maintained at or below $0.001 \%(\mathrm{v} / \mathrm{v})$. This DMSO concentration did not show any significant antiproliferative effect on the cell line in a short-term assay.

Colony-forming assay. Colony-forming assay was performed according to Rafehi et al (19). Briefly, 200 cells/well were plated in 6-well plates and allowed to adhere overnight. Cells were then treated with drugs in CM at the indicated concentration or with vehicle alone for $72 \mathrm{~h}$. After drug exposure cells were incubated with complete media for 7-10 days (media was changed every $72 \mathrm{~h}$ ). Then cells were fixed with $3.7 \%$ formaldehyde for $15 \mathrm{~min}$, stained with $0.01 \%$ crystal violet and photographed. Colonies were counted using ImageJ software (ImageJ v.1.48, http://imagej.nih.gov/ij/).

Statistic analysis. The drug concentrations inhibiting cell growth by $50 \%\left(\mathrm{IC}_{50}\right)$ were determined by interpolation from the dose-response curves using a sigmoidal logistic 3 parameters equation. Curve fitting was performed with SigmaPlot (v.11.0) software. Each point represents the mean \pm standard error (SE) of triplicate or quadruplicate wells (see figures for details). Comparison between groups has been done by ANOVA.

Combination index assay. The combination index (CI) was calculated to investigate the combined effect of Dig or MonoD and PX. The CI was calculated using the following formula (6): $\mathrm{CI}=\left[\mathrm{IC}_{50}(\mathrm{CG}+\mathrm{PX}) / \mathrm{IC}_{50}(\mathrm{CG}\right.$ alone $\left.)\right]+\left[\mathrm{IC}_{50}(\mathrm{PX}+\mathrm{CG}) / \mathrm{IC}_{50}\right.$ (PX alone)]. Where $\mathrm{CG}=\mathrm{Dig}$ or MonoD and $\mathrm{PX}=$ paclitaxel . $\mathrm{CI}>1$ was defined as antagonistic effect, $\mathrm{CI}=1$ as an additive effect, and CI $<1$ as a synergistic effect (20).

\section{Results}

Serum potentiates the antiproliferative effect of Dig but not of MonoD. Cells were seeded at 2,000 cells/well and allowed to adhere overnight, and treated with increasing doses of Dig or MonoD $(0,1,5,10,25,50,100$ or $200 \mathrm{nM})$ in CM for 24,48 or $72 \mathrm{~h}$. Cell viability was determined using MTT assay. Fig. 1 shows that cells incubated with Dig in SFM were less sensitive $\left(\mathrm{IC}_{50}\right.$ at $\left.24 \mathrm{~h}, 91.3 \pm 11.4\right)$ to this drug when compared to cells incubated in $\mathrm{CM}\left(\mathrm{IC}_{50}\right.$ at $\left.24 \mathrm{~h}, 29.4 \pm 2.1\right)$. The effect was maximal after $24 \mathrm{~h}$ and observed for up to $72 \mathrm{~h}$. In contrast, cells treated with MonoD showed similar sensitivity to this drugs in the absence $\left(\mathrm{IC}_{50}\right.$ at $\left.24 \mathrm{~h}, 29.4 \pm 2.1\right)$ or in the presence $\left(\mathrm{IC}_{50}\right.$ at $\left.24 \mathrm{~h}, 37.3 \pm 4.5\right)$ of $5 \%$ FBS. Table I shows the $\mathrm{IC}_{50}$ for 24,48 and $72 \mathrm{~h}$ and clearly indicates that the potency of Dig but not MonoD are potentiated when incubated in CM.

Short-term serum starvation attenuates the antiproliferative effects of both Dig and MonoD. Cells seeded at 2,000 cells/well were allowed to adhere overnight and later starved for $24 \mathrm{~h}$ in SFM. This procedure is widely used to synchronize and reversibly arrest cells at the $G_{0} / G_{1}$ transition of the cell cycle $(21,22)$. After starvation, cells were treated with Dig or MonoD $(0,1,5$, $10,25,50,100$ or $200 \mathrm{nM}$ ) in either SFM or CM for 24,48 or 72 h. Cell viability was determined by the MTT assay. Fig. 2 shows that serum starvation for $24 \mathrm{~h}$ attenuated the effect of both Dig and MonoD, suggesting that slow proliferating cells are less sensitive to both drugs. Table II shows the $\mathrm{IC}_{50}$ for 24 , 48 and $72 \mathrm{~h}$ following $24 \mathrm{~h}$ of serum starvation.

Hydroxyurea pretreatment does not affect the antiproliferative effect of Dig and MonoD. The differential effect of serum on the antiproliferative activity of Dig and MonoD and the effect of serum starvation on their activity prompted us to investigate whether CGs can be more effective in combination with drugs that act at specific phases of the cell cycle. We first evaluated the effect of Dig and MonoD in combination 
Table I. $\mathrm{IC}_{50}$ for digitoxin and MonoD at 24,48 or $72 \mathrm{~h}$.

\begin{tabular}{|c|c|c|c|c|c|c|}
\hline \multirow[b]{3}{*}{ H460 cells } & \multicolumn{6}{|c|}{$\mathrm{IC}_{50}($ mean $\pm \mathrm{SE})$} \\
\hline & \multicolumn{2}{|c|}{$24 \mathrm{~h}$} & \multicolumn{2}{|c|}{$48 \mathrm{~h}$} & \multicolumn{2}{|c|}{$72 \mathrm{~h}$} \\
\hline & SFM & $5 \% \mathrm{FBS}$ & SFM & $5 \%$ FBS & SFM & $5 \%$ FBS \\
\hline Digitoxin & $91.3 \pm 11.4$ & $29.4 \pm 2.1$ & $49.2 \pm 2.6$ & $24.7 \pm 1.3$ & $36.4 \pm 3.1$ & $19.4 \pm 1.7$ \\
\hline MonoD & $49.1 \pm 11.2$ & $37.3 \pm 4.5$ & $24.9 \pm 1.2$ & $22.3 \pm 0.9$ & $17.6 \pm 0.9$ & $19.6 \pm 1.1$ \\
\hline
\end{tabular}

FBS, fetal bovine serum; SFM, serum-free media.

Table II. $\mathrm{IC}_{50}$ for digitoxin and MonoD at 24, 48 or $72 \mathrm{~h}$ after $24 \mathrm{~h}$ serum starvation.

\begin{tabular}{|c|c|c|c|c|c|c|}
\hline \multirow[b]{3}{*}{ H460 cells } & \multicolumn{6}{|c|}{$\mathrm{IC}_{50}($ mean $\pm \mathrm{SE})$} \\
\hline & \multicolumn{2}{|c|}{$24 \mathrm{~h}$} & \multicolumn{2}{|c|}{$48 \mathrm{~h}$} & \multicolumn{2}{|c|}{$72 \mathrm{~h}$} \\
\hline & SFM & $5 \% \mathrm{FBS}$ & SFM & $5 \%$ FBS & SFM & $5 \%$ FBS \\
\hline Digitoxin & $100.41 \pm 28.3$ & $41.90 \pm 3.0$ & $47.32 \pm 9.4$ & $27.98 \pm 7.8$ & $43.78 \pm 12.7$ & $18.63 \pm 1.0$ \\
\hline MonoD & $88.78 \pm 13.4$ & $37.99 \pm 3.9$ & $46.27 \pm 7.8$ & $17.56 \pm 1.7$ & $39.87 \pm 6.2$ & $15.03 \pm 1.1$ \\
\hline
\end{tabular}

FBS, fetal bovine serum; SFM, serum-free media; SE, standard error.
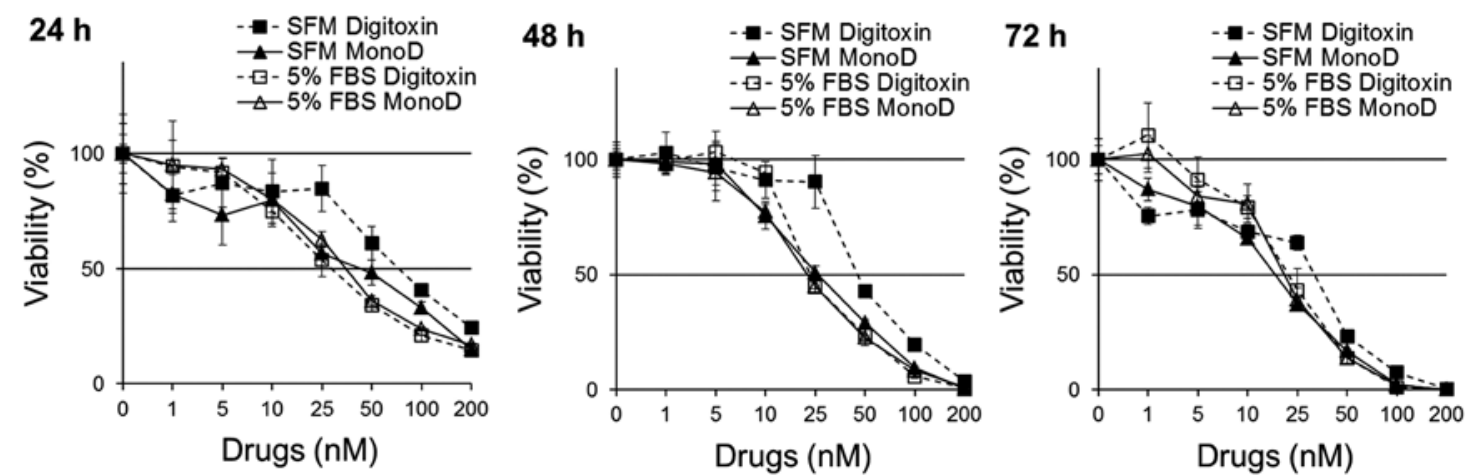

Figure 1. Serum potentiates the antiproliferative effect of digitoxin and MonoD. H460 cells were incubated in serum-free media or media $+5 \%$ FBS with 0,1 , $5,10,25,50,100$ or $200 \mathrm{nM}$ digitoxin or MonoD for 24,48 for $72 \mathrm{~h}$. Cell viability was assessed by the MTT assay after drug exposure for 24,48 or $72 \mathrm{~h}$. The table show the $\mathrm{IC}_{50} \pm \mathrm{ES}$ for each drug. Results are representative of two experiments performed by quadruplicates.
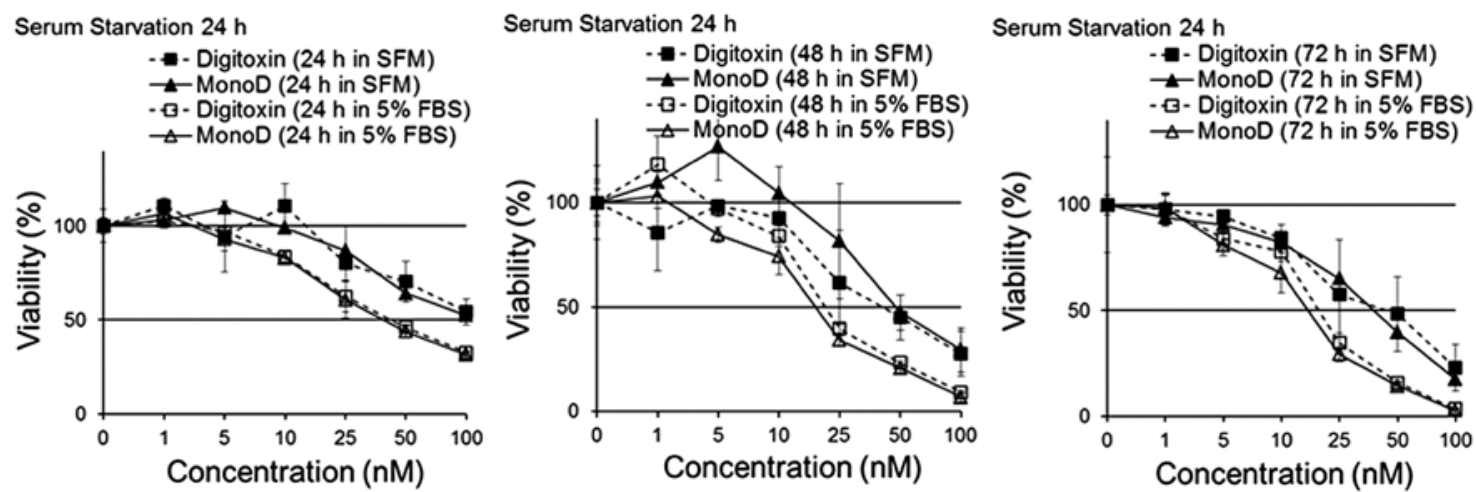

Figure 2. Short periods of serum starvation slightly attenuates the antiproliferative effect of digitoxin and MonoD. H460 cells were serum starved overnight and then incubated in serum-free media or media $+5 \%$ FBS with $0,1,5,10,25,50,100$ or $200 \mathrm{nM}$ Digitoxin or MonoD for 24,48 for $72 \mathrm{~h}$. Cell viability was assessed by the MTT assay after drug exposure for 24,48 or $72 \mathrm{~h}$. The table shows the $\mathrm{IC}_{50} \pm \mathrm{ES}$ for each drug. Results are representative of two experiments performed by quadruplicates. 
A
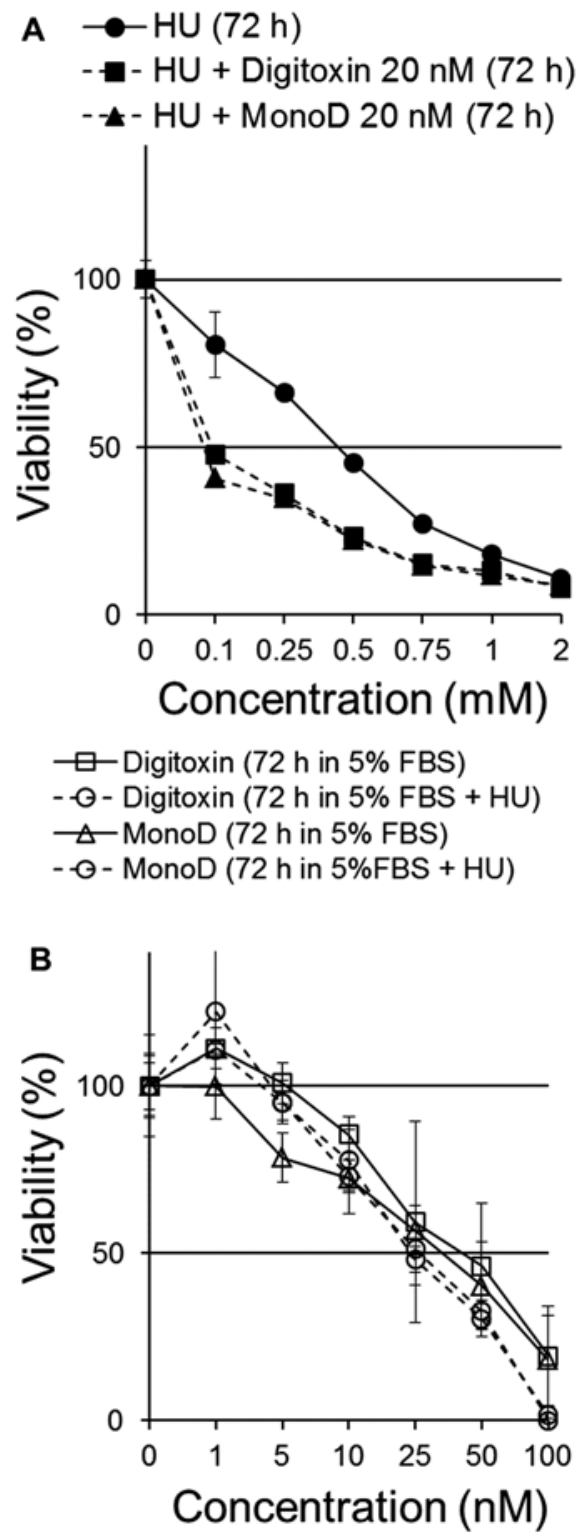

Figure 3. Effect of digitoxin and MonoD in combination with hydroxyurea (A) Concomitant treatment with Dig $20 \mathrm{nM}$ or MonoD $20 \mathrm{nM}$ increases the antiproliferative effect of HU. (B) Dig and MonoD exerts antiproliferative effect on cells that survived treatment with HU $2 \mathrm{mM}$ for $24 \mathrm{~h}$ with similar potency compared to HU-untreated cells.

with varying concentrations of HU. Dig and MonoD at $20 \mathrm{nM}$ were chosen since this concentration is close to their $\mathrm{IC}_{50}$. Cells were treated with $\mathrm{HU}(0,0.1,0.25,0.5,0.75,1$ or $2 \mathrm{mM})$ in CM for $72 \mathrm{~h}$ in the presence or absence of $20 \mathrm{nM}$ Dig or MonoD. Fig. 3A shows that both Dig and MonoD slightly increase the antiproliferative effect of $\mathrm{HU}$ when both drugs were added simultaneously. The $\mathrm{IC}_{50}$ for $\mathrm{HU}$ alone, $\mathrm{HU}+\mathrm{Dig}$ and $\mathrm{HU}+$ MonoD $20 \mathrm{nM}$ were $0,56 \pm 0.02,0.28 \pm 0.02$ and $0.27 \pm 0.01 \mathrm{mM}$, respectively.

We next investigated the effect of pretreatment with HU ( $2 \mathrm{mM}$ ) on the antiproliferative effect of Dig and MonoD. It is well established that HU-treated cells accumulate in early $\mathrm{S}$ phase due to a dose-dependent inhibiting effect of $\mathrm{HU}$ on DNA synthesis (23). Upon release from the block, cells synchronously progress through $\mathrm{S}, \mathrm{G}_{2}$ and $\mathrm{M}$ phases of the cell cycle (24). Cells seeded at 2,000 cells/well were allowed
Table III. IC $_{50}$ for paclitaxel, colchicine (routine culture), digitoxin and MonoD (prolonged serum starvation).

\begin{tabular}{lcc}
\hline & $\mathrm{IC}_{50}($ mean $\pm \mathrm{SD})$ & $\mathrm{IC}_{50}($ mean $\pm \mathrm{SD})$ \\
H460 cells & $48 \mathrm{~h}$ & $72 \mathrm{~h}$ \\
\hline Paclitaxel $(\mathrm{nM})$ & $8.93 \pm 0.7$ & $\mathrm{ND}$ \\
Colchicine $(\mu \mathrm{M})$ & $0.1815 \pm 0.02$ & $\mathrm{ND}$ \\
Dig $(\mathrm{nM})$ & $82.32 \pm 7.26$ & $88.66 \pm 8.12$ \\
MonoD $(\mathrm{nM})$ & $21.09 \pm 2.61$ & $19.15 \pm 1.52$ \\
\hline
\end{tabular}

ND, not determined; SD, standard deviation; Dig, digitoxin.

Table IV. IC $_{50}$ for paclitaxel, paclitaxel + digitoxin and paclitaxel + MonoD.

\begin{tabular}{lcc}
\hline & $\mathrm{IC}_{50}($ mean $\pm \mathrm{SD})$ & $\mathrm{IC}_{50}($ mean $\pm \mathrm{SD})$ \\
H460 cells & $48 \mathrm{~h}$ & $72 \mathrm{~h}$ \\
\hline Paclitaxel & $11.82 \pm 1.20$ & $10.22 \pm 0.55$ \\
Paclitaxel + digitoxin & $3.02 \pm 0.42$ & $2.71 \pm 0.33$ \\
$(20 \mathrm{nM})$ & & \\
Paclitaxel + MonoD & $3.39 \pm 0.48$ & $2.04 \pm 0.37$ \\
$(20 \mathrm{nM})$ & & \\
\hline
\end{tabular}

$\mathrm{SD}$, standard deviation.

to adhere overnight and later incubated for $24 \mathrm{~h}$ in CM in the presence of $2 \mathrm{mM} \mathrm{HU}$, which inhibited proliferation by $\sim 80-90 \%$ (Fig. 3A). The arrested/surviving cells were treated with Dig or MonoD $(0,1,5,10,25,50,100$ or $200 \mathrm{nM})$ in $\mathrm{CM}$ for $72 \mathrm{~h}$. Cell viability was determined by the MTT assay. Parallel cultures with HU-untreated cells were used for comparison. Fig. 3B shows that Dig and MonoD treatment for $72 \mathrm{~h}$ decreased the proliferation of HU-pretreated cells with a similar potency compared to HU-untreated cells. Overall, the data show that pretreatment with HU does not significantly affect the antiproliferative effect of Dig and MonoD, but suggests that CGs can still induce cytotoxicity in cells that survived HU treatment, thereby positing a potential role for CGs when added after HU.

Long-term serum starvation attenuates the antiproliferative effect of paclitaxel, colchicine, hydroxyurea and digitoxin but not MonoD. It is known that lung cancer cells can grow in serum-free media for prolonged period (25); however, the chemosensitivity of cells growing under this condition is poorly characterized. We first evaluated the antiproliferative effects of PX and colchicine on H460 cells in CM. Fig. 4A shows that H460 cells were highly sensitive to PX and colchicine ( $\mathrm{IC}_{50}, 8.9 \mathrm{nM}$ and $1.8 \mu \mathrm{M}$, respectively). Next we evaluated the effect of PX, colchicine, HU, Dig and MonoD on H460 cells serum-starved for prolonged periods: cells seeded at 2,000 cells/well were allowed to adhere overnight and later starved for 7-8 days in SFM. It is important to note that H460 cells grew in serum-free conditions at reduced proliferation rates (data not shown). After starvation, cells were treated 

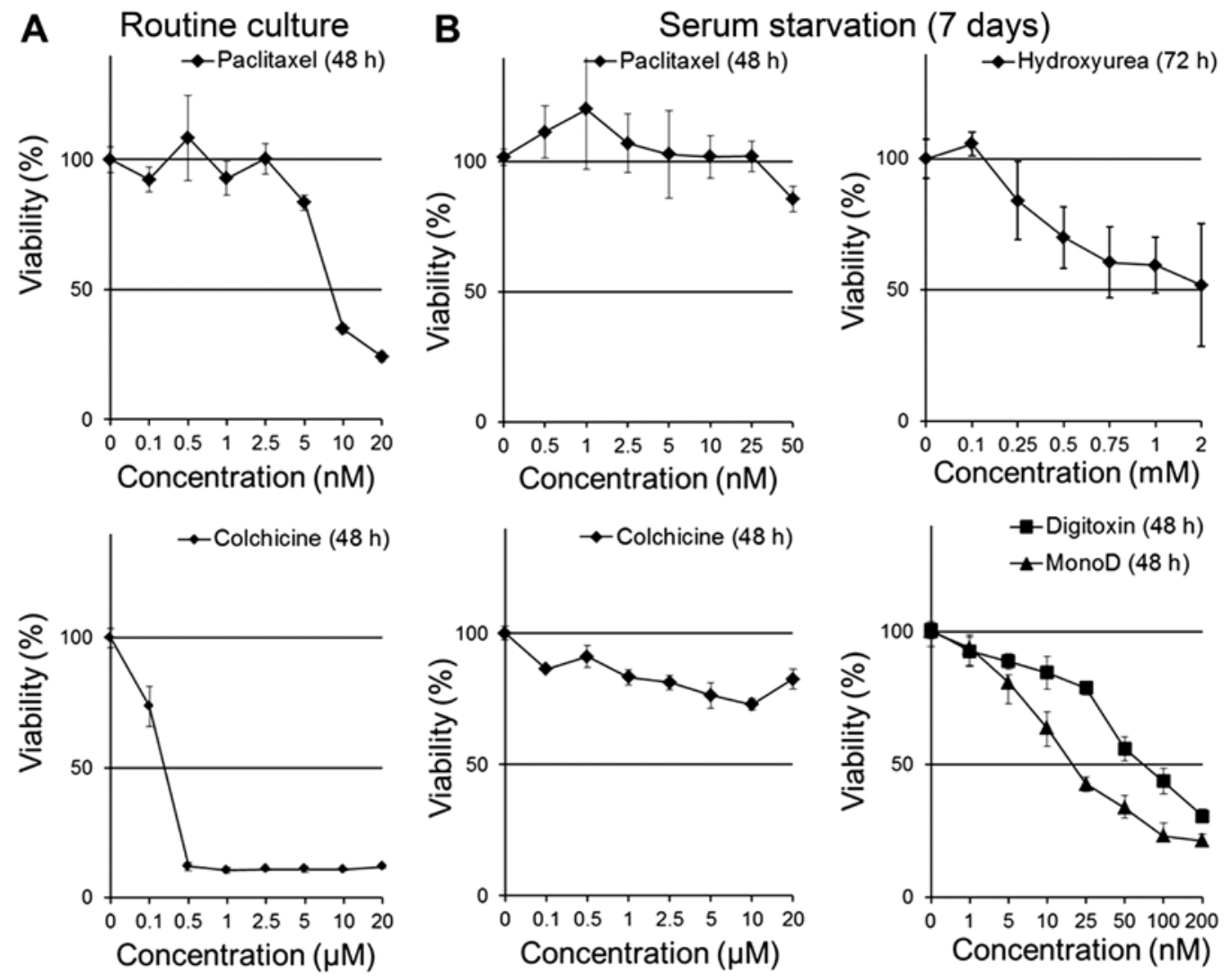

Figure 4. Prolonged periods of serum starvation slightly attenuates the antiproliferative effect of digitoxin and MonoD but markedly affect paclitaxel, colchicine and hydroxyurea sensitivity. (A) Effect of PX and colchicine on H460 cells growing in CM. Cells were treated with drugs in CM. (B) Effect of PX, colchicine, HU, Dig and MonoD on seven-day serum-starved H460 cells. Cells were treated with drugs in SFM. PX, paclitaxel; HU, hydroxyurea; Dig, digitoxin; SFM, serum-free media.

with Dig or MonoD $(0,1,5,10,25,50,100$ or $200 \mathrm{nM})$ in SFM for 24,48 or $72 \mathrm{~h}$. Cell viability was determined by the MTT assay. As shown in Fig. 4, following prolonged serum starvation, $\mathrm{H} 460$ cells became insensitive to $\mathrm{PX}$ and colchicine (Fig. 4B), less sensitive to HU and Dig but remain highly sensitive to MonoD (compare activity with Figs. 1-3). Table III shows the $\mathrm{IC}_{50}$ for paclitaxel, and colchicine in cells growing under routine culture conditions and for digitoxin and MonoD in cells growing under prolonged serum starvation. Table IV shows the $\mathrm{IC}_{50}$ of paclitaxel, paclitaxel + digitoxin and paclitaxel + MonoD.

Dig and MonoD synergize with paclitaxel on H460 cancer cells. PX exerts cytotoxic effects against $\mathrm{H} 460$ cells with $\mathrm{IC}_{50}$ ranging from $5 \mathrm{nM}(20)$ to $25 \mathrm{nM}$ (26). However, $24 \mathrm{~h}$ treatment with PX can induce a cell cycle arrest at the $\mathrm{G}_{2} / \mathrm{M}$ transition and this effect was observed to be maximum at a concentration that is $\sim 10$ times higher that its $\mathrm{IC}_{50}(27)$.

Cells seeded at 2,000 cells/well were allowed to adhere overnight and treated with $\mathrm{PX}(0,0.5,1,2.5,5,10,25$ or $50 \mathrm{nM})$ in the absence (vehicle alone, DMSO) or presence of Dig or MonoD (20 nM) in CM for 48 or $72 \mathrm{~h}$. Cell viability was determined by the MTT assay. The co-treatment showed increased antiproliferative activity compared to PX alone (Fig. 5) and the effect was found to be synergistic. Synergism was confirmed by the $\mathrm{CI}$ that was calculated using the $\mathrm{IC}_{50}$ from dose responses curves for Dig alone or MonoD alone (Fig. 1), PX alone and PX co-treated with either Dig or MonoD (Fig. 5).
The CI values were 0.404 and 0.403 for PX + Dig and $\mathrm{PX}+\mathrm{MonoD}$, respectively. The enhanced effect due to the co-treatment was also observed by the colony-forming assay. $\mathrm{H} 460$ cells were plated in 6-well plates at 200 cells/well and allowed to adhere overnight. Cells were then treated with drugs alone (PX $10 \mathrm{nM}$, Dig $20 \mathrm{nM}$ or MonoD $20 \mathrm{nM}$ ) or combined (PX $10 \mathrm{nM}+$ Dig $20 \mathrm{nM}$ or PX $10 \mathrm{nM}+$ MonoD $20 \mathrm{nM}$ ) for $72 \mathrm{~h}$. Cells treated with DMSO alone were included as control and equivalent DMSO concentrations were included in all treatment $(\sim 0.001 \%)$. Following drug treatment, cells were incubated in complete media for 10 days (media was changed every 3 days) and colonies were stained and quantified as described in the Materials and methods section. Fig. 5B shows that co-treatment with either PX $10 \mathrm{nM}+$ Dig $20 \mathrm{nM}$ or PX $10 \mathrm{nM}+$ MonoD $20 \mathrm{nM}$ has enhanced antiproliferative activity when compared to drugs alone.

Effect of sequential treatment of lung cancer cells in single or multi-drug modalities has alternative effects. PX combination treatments by other groups have demonstrated that sequential regimens can have additive, synergistic or antagonistic effects on cancer cell lines depending on the order in which the drugs are administered (20,28-30). Two types of sequential treatments were performed. In the first protocol (single drug $\rightarrow$ co-treatment) cells were treated with a single drug (PX, Dig or MonoD) for $24 \mathrm{~h}$, followed by PX + Dig or $\mathrm{PX}+\mathrm{MonoD}(\mathrm{PX} \rightarrow \mathrm{PX}+\mathrm{Dig}, \mathrm{PX} \rightarrow \mathrm{PX}+\mathrm{MD}$, respectively) for $48 \mathrm{~h}$. Cell viability was assessed using the MTT assay. 

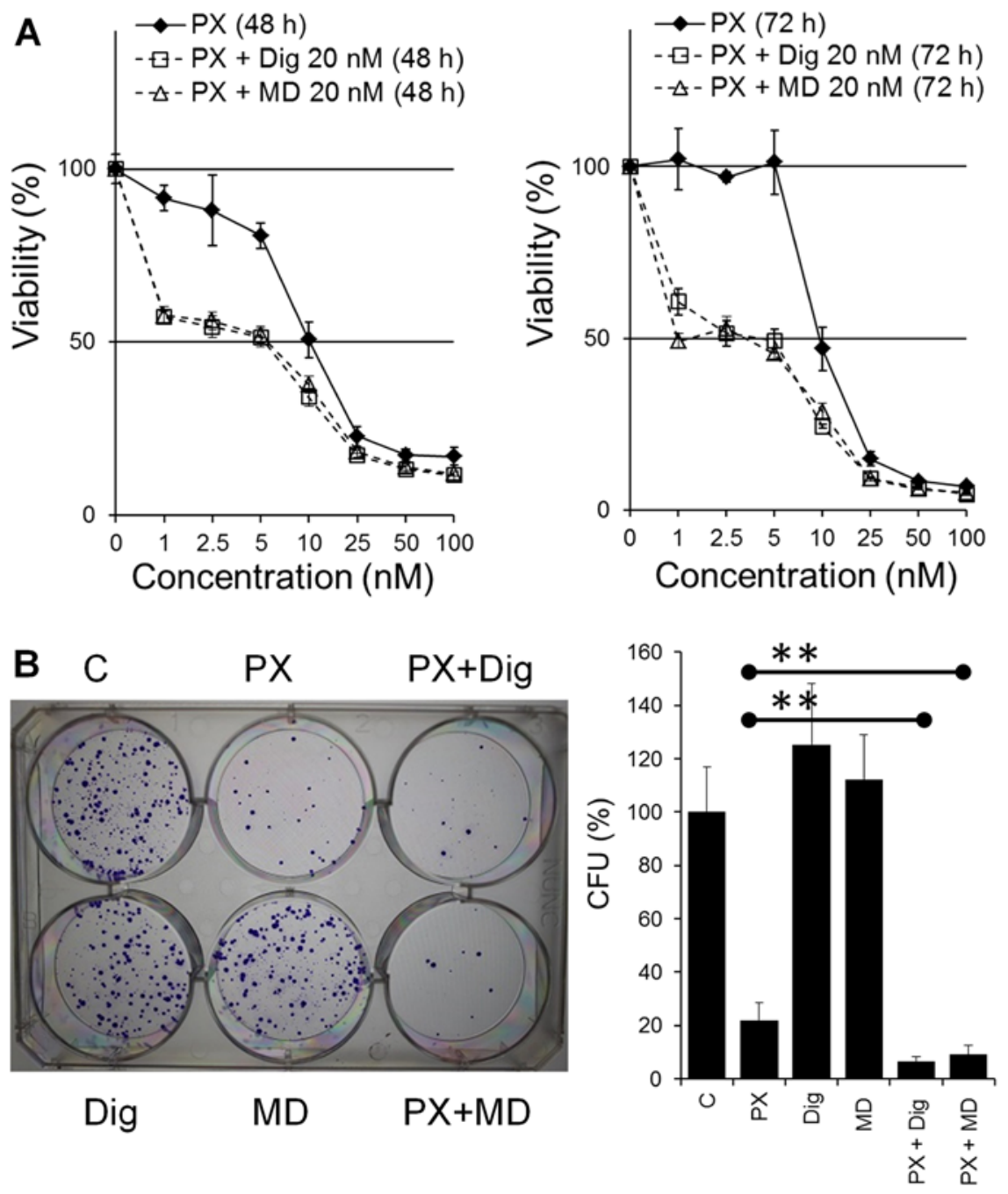

Figure 5. Effect of digitoxin and MonoD in combination with paclitaxel on H460 cancer cells. (A) Concentration-dependent effect of PX alone or in the presence of Dig $(20 \mathrm{nM})$ or MonoD $(20 \mathrm{nM})$. Cell viability was measured by the MTT assay after treatment for 48 or $72 \mathrm{~h}$. (B) Left panel, representative digital images showing colonies produced by H460 cells following plating of 200 cells. Cells were treated with Dig $(20 \mathrm{nM})$, MonoD (20 nM) or PX (10 nM) alone or in combination (PX $10 \mathrm{nM})+\operatorname{Dig}(20 \mathrm{nM})$ or MonoD $(20 \mathrm{nM})$ for $72 \mathrm{~h}$ in and then allowed to form colonies for 10 days. C, Control cells were treated with DMSO alone. Right, quantification of the colony forming assay. ${ }^{* *} \mathrm{P}<0.05$, significantly different between PX $10 \mathrm{nM}$ vs. the combined treatments. PX, paclitaxel; Dig, digitoxin.

These regimens were compared to single drugs alone incubated for the same period of time. To eliminate any potential effect of media consumption and/or drug inactivation during the first $24 \mathrm{~h}$, all media and drugs were freshly prepared and added at $24 \mathrm{~h}$. The same procedure with the reverse sequence was also performed (Dig $\rightarrow$ PX + Dig) (Fig. 6A and B). In the second protocol (single drug $\rightarrow$ single drug), cells were treated with a single drug (PX, Dig or MonoD) for $24 \mathrm{~h}$ followed by Dig or MonoD (PX $\rightarrow$ Dig, PX $\rightarrow$ MD, respectively) for $48 \mathrm{~h}$. The same procedure with the reverse sequence was also performed $($ Dig $\rightarrow$ PX) (Fig. 6C and D). Overall the results indicated that enhanced antiproliferative activity was obtained when PX was added first.

\section{Discussion}

Combination chemotherapy with drugs that show enhanced antitumor efficacy is considered a promising approach to improve clinical success by decreasing single drug doses and minimizing or slowing drug resistance development (31).
Drugs with different mechanisms of action, relative noncross-resistance, and partially non-overlapping toxicities are considered good candidates (29).

In this study we first demonstrated that Dig and MonoD have, at clinically relevant concentrations, potent antiproliferative activity against the human H460 lung cancer cell line and that there is a serum-dependent effect on the antiproliferative activity of Dig but not MonoD (Fig. 1).

Short periods of serum deprivation ( $24 \mathrm{~h}$ prior to the addition of drugs), a procedure known to increase the percentage of cells in the $G_{0} / G_{1}$ phase of the cell cycle, slightly decreased the effectiveness of both CGs (Fig. 2). The effect was more evident when cells were incubated with drugs in SFM for $24 \mathrm{~h}$. After $72 \mathrm{~h}$ of drug exposure, there was no significant difference in the potency of Dig and MonoD when compared to cells not subjected to starvation for $24 \mathrm{~h}$. It is important to mention that the $\mathrm{IC}_{50}$ of digitoxin for $\mathrm{H} 460$ cells subjected to short periods of starvation was still within the therapeutic range ( $<46 \mathrm{nM})$ (Fig. 2). When Dig (20 nM) or MonoD (20 nM) were used alone for $72 \mathrm{~h}$ in complete media, it led to decreased cell 
A

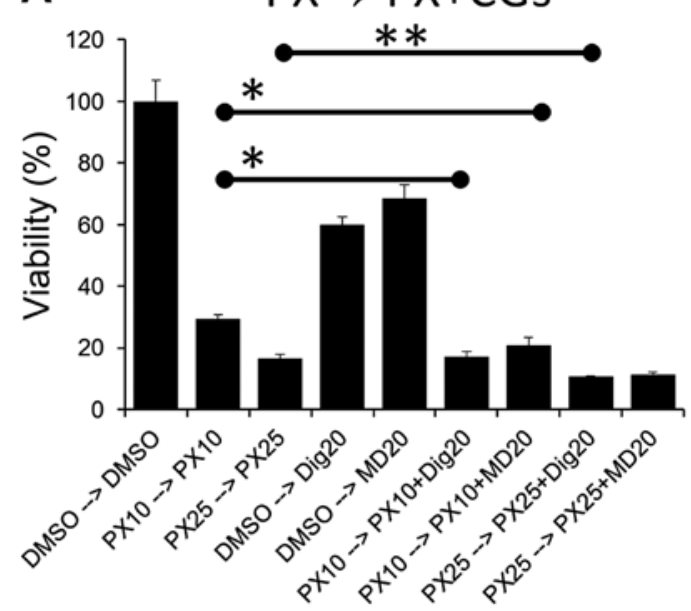

C

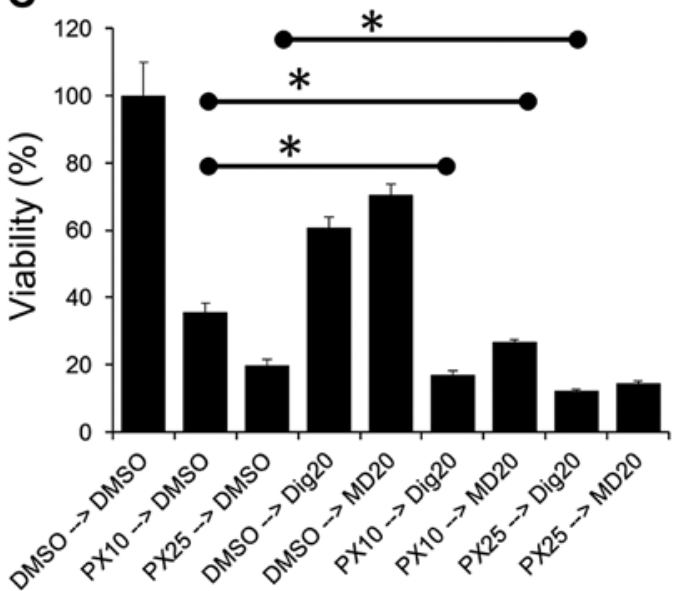

B

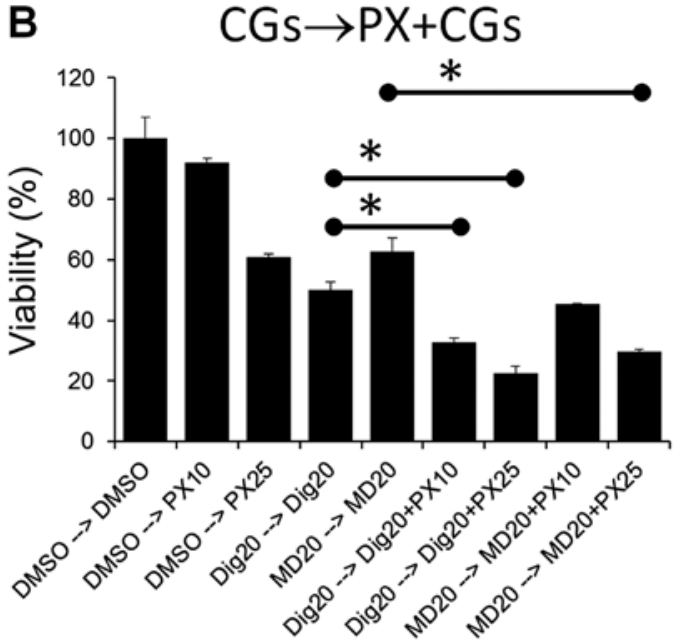

D
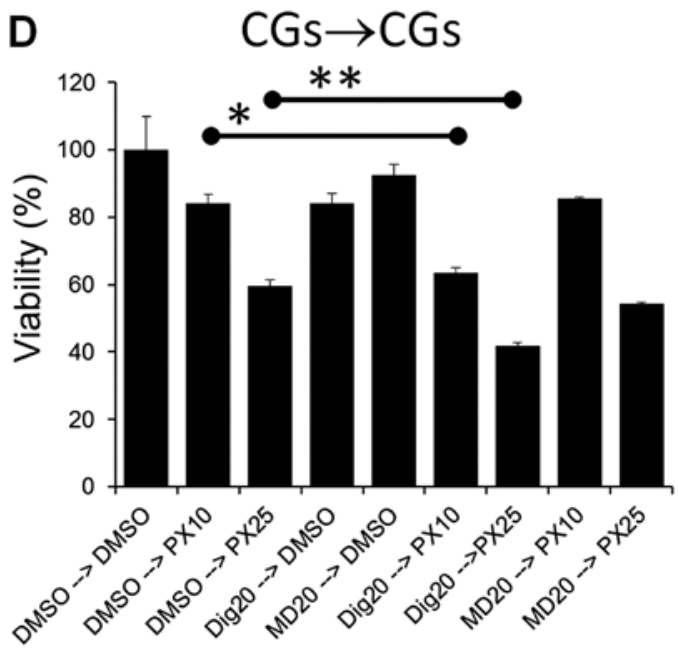

Figure 6. Sequential treatment: single drug $\rightarrow$ co-treatment (A and B) or single drug $\rightarrow$ single drug $(\mathrm{C}$ and D). Cells were incubated for $24 \mathrm{~h}$ with drugs alone at the indicated concentration for $24 \mathrm{~h}$ followed by incubation with the indicated combination or drug alone for $48 \mathrm{~h}$. The symbol '-->' indicates the sequence in which the drugs were added after $24 \mathrm{~h}$. Control cells (DMSO) were incubated with DMSO that was also included at equivalent concentrations for all treatments. ${ }^{*} \mathrm{P}<0.001$ and ${ }^{* *} \mathrm{P}<0.05$.

viability by $\sim 50 \%$ (Fig. $5 \mathrm{~A}$ ) in perfect agreement with their respective $\mathrm{IC}_{50}$ previously shown in Fig. 1. However, when both CGs were used alone at the same concentration (each at $20 \mathrm{nM}$ ) in the colony-forming assay they showed no effect compared to DMSO alone. This paradoxical effect is not due to experimental variations and may be explained by assuming that Dig and MonoD at $20 \mathrm{nM}$ have a reversible effect, which was confirmed subsequently (Fig. 6).

Both Dig and MonoD potentiated the effect of HU. HU at $0.75-1 \mathrm{mM}$ in combination with Dig $20 \mathrm{nM}$ or MonoD $20 \mathrm{nM}$ decreased the viability of $\mathrm{H} 460$ cells by $>80 \%$ (Fig. 3A). These are clinically relevant concentrations since a mean serum level of $\mathrm{HU}>1 \mathrm{mM}$ can be achieved and maintained in patients (13). Pretreatment with HU 2 mM, a concentration that slow down and partially synchronize cells in $\mathrm{S}$ phase inhibited the proliferation of $\mathrm{H} 460$ cells by $\sim 80 \%$ within $24 \mathrm{~h}$ (Fig. 3A). Cells that survived $2 \mathrm{mM} \mathrm{HU}$ for $24 \mathrm{~h}$ were sensitive to Dig or MonoD (Fig. 3B).

When grown in routine culture media supplemented with $5 \%$ FBS, H460 cells were very sensitive to HU (Fig. 3A), PX and colchicine (Fig. 4A). Prolonged serum deprivation (7 days) markedly decreased the antiproliferative activity of HU, PX and colchicine and decreased the effectiveness of Dig, but had no effect on MonoD (Fig. 4B). In fact, the antiproliferative effect of MonoD was high when the drugs were added in complete media ( $\mathrm{IC}_{50} \sim 20 \mathrm{nM}$ at $72 \mathrm{~h}$ ) (Fig. 1), low when cells were incubated in SFM for up to $96 \mathrm{~h}\left(\mathrm{IC}_{50} \sim 40 \mathrm{nM}\right.$ at 72 h) (Fig. 3), and again high when cells were incubated in SFM for 7 days $\left(\mathrm{IC}_{50} \sim 20 \mathrm{nM}\right.$ at $72 \mathrm{~h}$ ) (Fig. 4). The data suggest that MonoD exerts its antiproliferative action in a manner that is distinct from Dig, and that MonoD may potentially be a more suitable anti-neoplastic agent for the treatment of cancers that are not in the dividing phase and thus able to resist the effect of traditional chemotherapy including PX and HU.

The ability of CGs, especially MonoD, to kill cancer cells under different culture conditions compared to other drugs such as PX or colchicine is important since CGs may be less sensitive to intratumoral heterogeneity typically found in cancer tumors $(16,32)$. In this context, MonoD by its ability to kill cancer cells in the presence or absence of serum (a rich source of growth factors) with similar potency (Figs. 1, 3 and 4) offers an additional advantage.

Co-treatment of cancer cells with Dig + PX has been explored in vitro in a few types of cancer. Studies in the 
MDA-MB-453 breast cancer cell line showed a synergistic antiproliferative effect with Dig concentrations as low as $13 \mathrm{nM}$ (6). On the other hand, in the human prostate cancer cells (PC-3), Dig reversed both $\mathrm{G}_{2} / \mathrm{M}$ arrest and induction of apoptosis by PX (33). Based on these studies, it is clear that the effects of PX-based combinations are cell typedependent.

We explored the antiproliferative effects of PX + CGs combinations on $\mathrm{H} 460$ cells. We found that both Dig or MonoD in combination with PX have a synergistic effect (Fig. 5). In the present study we chose a fixed concentration of Dig $(20 \mathrm{nM})$ or MonoD $(20 \mathrm{nM})$ since these value are clinically relevant and close to their $\mathrm{IC}_{50}$ in serum containing media (Fig. 1).

PX in combination with other drugs showed antagonistic, additive or synergistic effect in a schedule-dependent manner (28-30). For this reason, we investigated sequential treatments (Fig. 6). Several important observations should be highlighted: i) maximal antiproliferative effect was obtained when PX (25 nM) was added as a first drug for $24 \mathrm{~h}$ followed by $20 \mathrm{nM}$ of either Dig or MonoD (Fig. 6A). However, this effect was only slightly higher when compared to PX followed by only one CG (20 nM Dig or MonoD) (Fig. 6C). ii) The maximum antiproliferative effect obtained with PX $25 \rightarrow 20 \mathrm{nM}$ of either Dig or MonoD was only slightly higher when compared to PX $25 \mathrm{nM}$ alone for $72 \mathrm{~h}$ (Fig. 6A). iii) The effect of $24 \mathrm{~h}$ treatment with the CGs were almost completely reversible, when cells treated for $24 \mathrm{~h}$ with either $20 \mathrm{nM}$ Dig or MonoD were incubated for $48 \mathrm{~h}$ in drug free media (DMSO alone), the proliferative activity was similar to control values (Fig. 6D). In contrast, the effects of either 10 or $25 \mathrm{nM}$ PX were irreversible: cells treated for $24 \mathrm{~h}$ with PX followed by $48 \mathrm{~h}$ in drug-free media (DMSO alone) demonstrated proliferative activity that was only slightly higher to cells treated with equivalent PX concentrations for $72 \mathrm{~h}$ (compare 10 and $20 \mathrm{nM}$ PX alone in Fig. 6C vs. D). The irreversible effect of PX could be due to the intracellular accumulation of this drug that can reach concentration levels up to $9 \mu \mathrm{M}$, and is likely retained in tumor tissue for a substantial period of time (11). The intracellular uptake of PX may explain the increased antiproliferative activity of PX-based combinations when PX is added first.

Overall, the aforementioned observations are important since sequential treatment with drugs $(\mathrm{PX} \rightarrow \mathrm{Dig}$ or MonoD) will be likely less toxic for several reasons: i) the exposure time to PX, due to its irreversible effect can be shortened and, ii) the doses of both drugs can be reduced, limiting potential adverse effects. Despite the fact that the antiproliferative effects of Dig and MonoD as single drugs were partially reversible (Figs. 5 and 6), both drugs were able to significantly increase the antiproliferative effect of PX in the colonyforming assay (Fig. 5), and demonstrate that the combination of PX + CGs have long-term antiproliferative effects. Therefore PX-CGs, and especially PX in combination with MonoD have the potential to target wider subpopulations of cancer cells.

Due to intratumor heterogeneity, the poor antiproliferative activity of PX on serum starved cells as well as the reversible effect of Dig and MonoD may limit the in vivo efficacy of the drug combinations described above. Furthermore, lung cancer stem cells that are able to grow in serum-free media (with few additives such as FGF and EGF) are known to be resistant to PX (34). To circumvent these limitations, other PX analogs with enhanced antiproliferative activity to serum starved cells and cancer stem cells, and Dig analogs similar to MonoD but with irreversible effects can be screened for testing new combinations with higher efficacy toward cancer cells that are resistant to traditional chemotherapeutic regimens.

In conclusion, we reported that both Dig and MonoD have potent antiproliferative activity against the chemoresistant NSCLC NCI-H460 cell line. Our studies have demonstrated that both CGs potentiated the antiproliferative effects of $\mathrm{HU}$ and PX, two anticancer drugs with different mechanism of actions. We also showed that sequential administration of PX followed by either Dig or MonoD resulted in the most significant cytotoxic effects. The latter has implications for rational translation of chemotherapeutic regimens for the treatment of lung cancer. Finally, by testing the efficacy of anticancer drugs in cells growing under different culture conditions (short and prolonged serum starvation) it was possible to identify that MonoD, contrary to PX, colchicine or HU, has potent antiproliferative activity against cells growing under prolonged serum starvation conditions. These studies offer a new strategy to screen and develop drugs and combinations of drugs that have higher probabilities of success in clinical trials.

\section{Acknowledgements}

This study was supported by grants CA173069 from the National Cancer Institute (NIH/NCI) to A.I. and HL112630 to N.A.

\section{References}

1. Coughlin SS, Matthews-Juarez P, Juarez PD, Melton CE and King M: Opportunities to address lung cancer disparities among African Americans. Cancer Med 3: 1467-1476, 2014.

2. Detterbeck FC, Mazzone PJ, Naidich DP and Bach PB: Screening for lung cancer: Diagnosis and management of lung cancer, 3rd ed: American College of Chest Physicians evidence-based clinical practice guidelines. Chest 143 (Suppl 5): e78S-e92S, 2013.

3. Nana-Sinkam SP and Powell CA: Molecular biology of lung cancer: Diagnosis and management of lung cancer, 3rd ed: American College of Chest Physicians evidence-based clinical practice guidelines. Chest 143 (Suppl 5): e30S-e39S, 2013.

4. López-Lázaro M, Pastor N, Azrak SS, Ayuso MJ, Austin CA and Cortés F: Digitoxin inhibits the growth of cancer cell lines at concentrations commonly found in cardiac patients. J Nat Prod 68: 1642-1645, 2005.

5. Kometiani P, Liu L and Askari A: Digitalis-induced signaling by $\mathrm{Na}^{+} / \mathrm{K}^{+}$-ATPase in human breast cancer cells. Mol Pharmacol 67: 929-936, 2005.

6. Einbond LS, Wu HA, Su T, Chang T, Panjikaran M, Wang X and Goldsberry S: Digitoxin activates EGR1 and synergizes with paclitaxel on human breast cancer cells. J Carcinog 9: 10, 2010.

7. Elbaz HA, Stueckle TA, Tse W, Rojanasakul Y and Dinu CZ: Digitoxin and its analogs as novel cancer therapeutics. Exp Hematol Oncol 1: 4, 2012.

8. Socinski MA: Update on taxanes in the first-line treatment of advanced non-small-cell lung cancer. Curr Oncol 21: e691-e703, 2014.

9. Lück HJ and Roché H: Weekly paclitaxel: An effective and well-tolerated treatment in patients with advanced breast cancer. Crit Rev Oncol Hematol 44 (Suppl): S15-S30, 2002.

10. Das V, Stěpánková J, Hajdúch M, and Miller JH: Role of tumor hypoxia in acquisition of resistance to microtubule-stabilizing drugs. Biochim Biophys Acta 1855: 172-182, 2015.

11. Zasadil LM, Andersen KA, Yeum D, Rocque GB, Wilke LG, Tevaarwerk AJ, Raines RT, Burkard ME and Weaver BA: Cytotoxicity of paclitaxel in breast cancer is due to chromosome missegregation on multipolar spindles. Sci Transl Med 6: 229ra43, 2014. 
12. Wiernik PH, Schwartz EL, Strauman JJ, Dutcher JP, Lipton RB and Paietta E: Phase I clinical and pharmacokinetic study of taxol. Cancer Res 47: 2486-2493, 1987.

13. Veale D, Cantwell BM, Kerr N, Upfold A and Harris AL: Phase 1 study of high-dose hydroxyurea in lung cancer. Cancer Chemother Pharmacol 21: 53-56, 1988.

14. Kang SR, Song HC, Byun BH, Oh JR, Kim HS, Hong SP Kwon SY, Chong A, Kim J, Cho SG, et al: Intratumoral metabolic heterogeneity for prediction of disease progression after concurrent chemoradiotherapy in patients with inoperable stage III non-small-cell lung cancer. Nucl Med Mol Imaging 48: 16-25, 2014.

15. Neelakantan D, Drasin DJ and Ford HL: Intratumoral heterogeneity: Clonal cooperation in epithelial-to-mesenchymal transition and metastasis. Cell Adh Migr 9: 1-12, 2015.

16. Cheng $X$ and Chen $\mathrm{H}$ : Tumor heterogeneity and resistance to EGFR-targeted therapy in advanced nonsmall cell lung cancer: Challenges and perspectives. Onco Targets Ther 7: 1689-1704, 2014.

17. Iyer AK, Zhou M, Azad N, Elbaz H, Wang L, Rogalsky DK, Rojanasakul Y, O'Doherty GA and Langenhan JM: A direct comparison of the anticancer activities of digitoxin MeON-Neoglycosides and O-Glycosides: Oligosaccharide chain length-dependent induction of caspase-9-mediated apoptosis ACS Med Chem Lett 1: 326-330, 2010.

18. Medan D, Luanpitpong S, Azad N, Wang L, Jiang BH, Davis ME, Barnett JB, Guo L and Rojanasakul Y: Multifunctional role of $\mathrm{Bcl}-2$ in malignant transformation and tumorigenesis of Cr(VI)-transformed lung cells. PLoS One 7: e37045, 2012.

19. Rafehi H, Orlowski C, Georgiadis GT, Ververis K, El-Osta A and Karagiannis TC: Clonogenic assay: Adherent cells. J Vis Exp 49: 2573, 2011

20. Park S, Kim JH, Hwang YI, Jung KS, Jang YS and Jang SH Schedule-dependent effect of epigallocatechin-3-gallate (EGCG) with paclitaxel on H460 cells. Tuberc Respir Dis (Seoul) 76 : 114-119, 2014.

21. Kues WA, Anger M, Carnwath JW, Paul D, Motlik J and Niemann H: Cell cycle synchronization of porcine fetal fibroblasts: Effects of serum deprivation and reversible cell cycle inhibitors. Biol Reprod 62: 412-419, 2000.

22. Khammanit R, Chantakru S, Kitiyanant Y and Saikhun J: Effect of serum starvation and chemical inhibitors on cell cycle synchronization of canine dermal fibroblasts. Theriogenology 70: 27-34, 2008.

23. Maurer-Schultze B, Siebert M and Bassukas ID: An in vivo study on the synchronizing effect of hydroxyurea. Exp Cell Res 174: 230-243, 1988
24. Darzynkiewicz Z, Halicka HD, Zhao H and Podhorecka M: Cell synchronization by inhibitors of DNA replication induces replication stress and DNA damage response: Analysis by flow cytometry. Methods Mol Biol 761: 85-96, 2011.

25. Brower M, Carney DN, Oie HK, Gazdar AF and Minna JD Growth of cell lines and clinical specimens of human non-small cell lung cancer in a serum-free defined medium. Cancer Res 46 798-806, 1986.

26. Soriano AF, Helfrich B, Chan DC, Heasley LE, Bunn PAJ Jr and Chou TC: Synergistic effects of new chemopreventive agents and conventional cytotoxic agents against human lung cancer cell lines. Cancer Res 59: 6178-6184, 1999.

27. Kroep JR, Giaccone G, Tolis C, Voorn DA, Loves WJ, Groeningen CJ, Pinedo HM and Peters GJ: Sequence dependent effect of paclitaxel on gemcitabine metabolism in relation to cell cycle and cytotoxicity in non-small-cell lung cancer cell lines. $\mathrm{Br}$ J Cancer 83: 1069-1076, 2000.

28. Zoli W, Ricotti L, Barzanti F, Dal Susino M, Frassineti GL, Milandri C, Casadei Giunchi D, and Amadori D: Scheduledependent interaction of doxorubicin, paclitaxel and gemcitabine in human breast cancer cell lines. Int J Cancer 80: 413-416, 1999.

29. Oliveras-Ferraros C, Vazquez-Martin A, Colomer R, De Llorens R, Brunet J and Menendez JA: Sequence-dependent synergism and antagonism between paclitaxel and gemcitabine in breast cancer cells: The importance of scheduling. Int J Oncol 32: 113-120, 2008.

30. Cheng H, An SJ, Zhang XC, Dong S, Zhang YF, Chen ZH, Chen HJ, Guo AL, Lin QX and Wu YL: In vitro sequencedependent synergism between paclitaxel and gefitinib in human lung cancer cell lines. Cancer Chemother Pharmacol 67: 637-646, 2011.

31. Baldan F, Mio C, Allegri L, Puppin C, Russo D, Filetti S and Damante G: Synergy between HDAC and PARP inhibitors on proliferation of a human anaplastic thyroid cancer-derived cell line. Int J Endocrinol 2015: 978371, 2015.

32. Gerlinger M, Rowan AJ, Horswell S, Larkin J, Endesfelder D, Gronroos E, Martinez P, Matthews N, Stewart A, Tarpey P, et al: Intratumor heterogeneity and branched evolution revealed by multiregion sequencing. N Engl J Med 366: 883-892, 2012.

33. Huang DM, Guh JH, Huang YT, Chueh SC, Wang HP and Teng CM: Cardiac glycosides induce resistance to tubulindependent anticancer drugs in androgen-independent human prostate cancer. J Biomed Sci 9: 443-452, 2002.

34. Larzabal L, El-Nikhely N, Redrado M, Seeger W, Savai R and Calvo A: Differential effects of drugs targeting cancer stem cell (CSC) and non-CSC populations on lung primary tumors and metastasis. PLoS One 8: e79798, 2013. 